\title{
Online Education: Trends and Risks of Digital Technologies
}

\author{
Svetlana Ilynykh ${ }^{1 *}$ \\ ${ }^{l}$ Novosibirsk State University of Economics and Management, Russia \\ "Email: ili.sa@mail.ru
}

\begin{abstract}
Purpose: to consider the specifics of online education in the context of trend lines, as well as digital technologies playing a significant role in education. Research subject: online education trends that capitalize on education and enable investment in the future. Materials and methods: the research is based on comparative analysis, interdisciplinary approach. The theoretical study is based on conceptual works and research results by Russian and foreign authors devoted to the analysis of online education. The article presents the results of an empirical study. Results: Online education is increasingly demanding and innovative ways of delivering quality content are searching for. In this regard, online education is attracting more and more attention to both sides of the educational process - students and teachers. Among the undoubted advantages is the acquisition of knowledge that, for one reason or another, the student is not able to have in an offline format. The most common reasons include, for example, the problem of knowledge obsolescence and the desire of students to master the latest trends. Thus, the individual can remain in the stream of the latest professional knowledge and trends. Other motives for obtaining online education include firstly, economic accessibility, secondly, the convenience of the acquiring knowledge format, thirdly, the possibility of establishing a convenient time frame for training, and fourthly, the possibility of obtaining additional knowledge. At the same time, online learning as an innovative learning format is fraught with evident and implicit risks. The article analyzes the risks of online education based on empirical results. Conclusion: online learning, on the one hand, creates the need for lifelong learning, creates opportunities for a wide range of students to receive education, on the other hand, it has limitations and risks. Today, Russian universities are required to prepare teachers to use digital teaching materials and improve technical support.
\end{abstract}

Keywords: Education, Russian universities, Online learning, Digital competence, Program learning, Competition.

\section{INTRODUCTION}

Digital technologies are increasingly entering the field of education. The availability of information resources to all categories of citizens creates the basis for obtaining education in a new format.

For the first time, online learning appeared in the world in 2008. It is related to the name of Indiana University professor Daniel Hickey, who is the author of the course "Practice Evaluation, Principles and Strategies". The novelty of the educational format was the training of 500 students, which was funded by Google [1]. The results of the course were positive, although a very significant dropout rate was noted.
In Russian education, the active introduction of massive online courses took place at the end of 2013. A more significant breakthrough was observed in the 20142015 academic year. Researchers regard the emergence of MOOCs as one of the most promising trends in the development of education [2].

Today, the essence of MOOCs and their history is devoted to a lot of research by such Russian scientists as S.L. Timkin [3], T.V. Semenova, K.A. Vilkov [4], Ya.M. Roshchina, S.Yu. Roshchin, V.N. Rudakov [5], as well as foreign researchers J. Deng [6], S.H. Foerster [7], B. Grainger [8] et al. Researchers consider a relatively wide range of issues, from undoubted advantages to the implicit problems of innovative teaching methods. 
Online education has several undeniable advantages, including the formation of a professional culture based on the desire for self-improvement using digital technologies and information services. However, given the unconditional significance of digital technologies, certain risks arise, which actualizes the need for a more thorough study of them.

\section{TRENDS OF ONLINE EDUCATION}

The first trend: investment in education - investment in the future

Online learning is now gaining increasing recognition as an innovative way to get an education, which today is becoming a kind of capital. Therefore, the use of new methods of obtaining an education is interpreted from the standpoint of investing in one's own future. However, the wider prevalence of this method of acquiring knowledge is associated with greater requirements for its organization.

\section{Second trend: "massification" of education}

Digital technologies in education, implemented in the format of online learning, allow individuals who do not have significant resources - financial, time, professional, etc. - to receive an education for this. As Daphne Koller points out, online services for developing countries are the only way to close the education gap and equip students with the skills they need in the 21 st century. Traditional education models cannot scale fast enough. Coursera offers an alternative way to distribute quality content to the people who need it the most [9].

Due to the availability of information services, massive open online courses provide an opportunity, in whole or in part, to have free access to educational resources of the world's leading universities. Innovation in online learning is the use of asynchronous, timespaced, and synchronous learning models. The latter format is carried out in the form of webinars, videoconferences. Significantly, the structure of a massive online educational course can change by the needs of specific participants.

The third trend: leadership and competition among universities

Although online education currently coexists with the traditional form in Russian education, the issue of leadership and competition is already emerging. Russian universities are quite actively involved in the process of creating online courses. Currently, this process has become even more noticeable, which is associated with the changes prospects in the universities activities. Thus, on the website of the Ministry of Education and Science in the tender documentation, we find that by 2024 at least $20 \%$ of students in educational programs of higher education are mastering specific courses, disciplines, including in the format of online courses. Here, it is relevant to use the resources of other educational organizations that ensure that the quality of training of students is consistent with the world level [10].

In other words, the Ministry of Education and Science orients Russian universities both to create their online courses and to the mandatory use of online resources of other universities. This, of course, creates a competitive environment among higher education institutions for online students. According to T.V. Semenova, L.M. Rudakova, the demand for online education is increasing by an average of $23 \%$ of Russians per year [11]. It seems to us that soon, the process of priority will emerge sharply among universities. The leadership of universities in the online education market will be determined by how successfully universities will work with data on how MOOC students behave [12].

\section{The fourth trend: the internalization of education}

It manifests itself in the fact that today local educational spaces are expanding and included in the global educational space. Thus, Tomsk State University joined the "Coursera for Campus" program. The online courses of Tomsk State University, hosted on this largest international platform, have become available all over the world for students of partner universities of the platform under the "Coursera for Campus" program [13]. TSU is one of the top-thirty Coursera partners, which differ in the quality and number of courses. At the same time, it is also one of eight Russian universities that are partners of the educational platform. Another leading Siberia University, Novosibirsk State University, entered the global online education market in 2015 [14]. The first were courses in genetics and the basics of virology.

\section{Fifth trend: the concept of continuing education}

Due to its advantages, which will be discussed below, online education supports the individual's need for learning. With online learning, the individual has real opportunities to satisfy it. Also, some universities integrate MOOC programs into higher and continuing education programs [15].

\section{ADVANTAGES AND LIMITATIONS OF ONLINE EDUCATION}

Online learning has both advantages and limitations. Let's consider some of the benefits of online learning, using macro- and micro-sociological approaches. In the first case, let us use the structural and functional paradigm of T. Parsons [16]. Speaking about education, the scientist assumes that situations inevitably arise in which a capable student can intentionally show lower results, restrain himself, since he must comply with the prescriptions of a certain group and a certain status. These arguments of $\mathrm{T}$. Parsons are also applied of Russian education. A student who has both high abilities and low social status can experience serious problems 
when entering the educational system. Conversely, a student with very mediocre abilities and high status has great preferences. Online learning helps to reduce the mismatch of abilities and status of the individual.

In the second case, the advantages of online learning can be identified based on the views of J.F. Lyotard [17, p.120]. He expresses a rather interesting idea. When studying at a university, there are several categories of students who in the future will join the ranks of the "professional intellectuals", "technical intellectuals", as well as potential unemployed who are not considering by statistics. The last category is formed due to the redundancy of the student's number to the employment system needs in the speciality received. However, at the same time, they are a new category - recipients of transmitted knowledge. Interpreting this idea about online learning, we can say that the need for an innovative way of obtaining an education can be high due to the sufficiently large number of recipients of knowledge, as well as the possible need to acquire completely new knowledge.

In addition to these advantages, which we highlighted based on macro and micro approaches, there are others. These include firstly, the availability of training, which is ensured by the fact that there are no significant initial requirements for training; also, there is a flexible training schedule [18]. The student is at home, in a familiar environment and receives knowledge at a convenient time for him. Significant, in this case, is that the opportunities for obtaining education for categories of students with health limitations are expanding. Secondly, the opportunity to gain new knowledge of their professional topics. Thirdly, the opportunity to gain new knowledge on an exciting topic that is not related to the profession. Fourthly, expanding your social connections. Fifthly, the opportunity to participate in a new form of interaction between students and teachers. Participants in the process communicate through social networks (YouTube, Twitter). For interaction, innovative means of communication are used, namely lectures in video format, social networks, forums, chats.

The attractiveness of online learning provides more significant potential for attracting students, including students with low socioeconomic status. As we have already indicated, it influences the formation and development of the concept of lifelong learning.

Despite the attractiveness of massive online courses, they also have some limitations - content, pedagogical, organizational, etc. One of the significant limitations is the digital competence of teachers. It seems to us that there can be difficulties of a very different order, from technical to content related to the quality of content.

As for technical difficulties, the video lectures must be recorded on professional equipment using directing. Thus, TSU uses more than 25 filming locations for the entire time of work on a MOOC project [15]. Therefore, "amateur" recording can negatively affect the reputation of the entire online course.

Researchers also note among the pedagogical limitations the use of a behavioural teaching model. Thus, T. Bates calls this model of teaching outdated pedagogy, a poor-quality form of teaching, which is suitable only for unpretentious students [19]. The traditional behavioural model is based on the method of programmed learning, the basis of which is the independent acquisition of knowledge and skills through the step-by-step assimilation of the material. However, here the reliance is not only on the transfer of information, the performance of tasks that are checked by a computer, the assessment of knowledge but also on the possibility of interactive communication between students and teachers.

Of no small importance are technical limitations associated with the technical capabilities of the Internet, first of all - the low speed of information transfer using telecommunication networks, as well as the instability of communication. Probably for this reason, they are used mainly by students from metropolis. Their share reaches $80 \%$ (according to Uniweb) [11].

There is no direct interaction with the learners during training on online platforms. In situations where the proposed material is not clear enough, this circumstance can serve as an obstacle for further training.

Generally, online training is designed for a fairly large amount of self-study of the material. On the one hand, it stimulates a person's cognitive abilities, but on the other hand, it helps to reduce self-motivation.

The considered limitations are not exhaustive, but at the same time, play a significant role in the promotion and implementation of innovative teaching methods.

\section{RISKS OF MASS ONLINE LEARNING}

Let's dwell on the risks of massive online learning. One of these is the dropout of students. Completion of the course is approximately 5 to $30 \%$ of the trainees. Note that this is a low percentage of graduates. According to R. Mayer, only $7 \%$ of the total number of students completed their studies in full on Coursera [20]

The motivation for leaving a massive online course can vary. In particular, this may be a decrease in interest in the online course content while maintaining the novelty of such courses. Of course, digital technologies in education always attract a certain share of curious teachers and students from other universities. At the same time, the form of organization of training seems to be interesting and attractive, and not the content side.

A study of the factors affecting dropout from online education showed that there is some correlation between 
academic performance and gender, age periods, and a correlation between academic performance and the level of student training. Self-regulation, in combination with locus control, was also essential [21]. Of course, these factors are also crucial for the traditional form of education, but for online, they turn out to be even more significant.

V.S. Makarov provides quite interesting data related to the disposal of the foreign example. Thus, for 17 courses offered by Harvard University and MITB, 841,687 students enrolled. $5 \%$ of trainees received a certificate and completed the courses $(43,196) .4 .2 \%$ of students $(35,937)$ completed the course more than half. $55.8 \%$ of listeners $(469,702)$ completed less than half of the assignments, $34.8 \%(292,852)$ did not even start working in a massive online course [22]. From the data presented, it can be seen that $5 \%$ completed the training. However, attention is drawn to the fact that a third of the respondents did not begin to study the course.

The study by T.V. Semenova and L.M. Rudakova is interesting for Russian education in the online format. A fairly significant proportion of 65 to $80 \%$ of students intends to complete the course. But only 6 to $31 \%$ complete the course. We have already indicated above, and here the authors also agree that gender and age influence the success of the course completion. According to the study, $20 \%$ of men and $14 \%$ of women complete their training. Of course, the motivation to complete online education is also significant. According to the results obtained, of all those who completed the training, $15 \%$ had the intention to complete the course to the end, and $9 \%$ did not have such plans.

Thus, the risks associated with online learning depend on a number of factors. Another factor is educational experience. Russian experience shows that successful completion of the course is more typical for students with higher education, as well as a learning experience in the online format.

\section{CONCLUSION}

Digitalization today is actively involved in all spheres of society. The introduction of online learning as innovative technologies in education is becoming a vital necessity because it is important to respond to the modern needs of students promptly. Online learning, on the one hand, creates the need for lifelong learning, creates opportunities for a wide range of students to receive education; on the other hand, it has limitations and risks. However, the process of introducing innovative educational technologies has already been launched; therefore, Russian universities today are required to prepare teachers for the use of digital educational materials and improve technical support.

The transition to a new era in education has taken place. Therefore, it is now essential to make the transition to educational processes based on the principles of cooperation and competition. It is essential to make the transition to learning in virtual environments, and for this, we repeat, it is necessary to form new skills of the teaching staff.

\section{REFERENCES}

[1] M.B. Lebedeva, Massive open online courses as a trend in the development of education, Man and education 1(42) (2015) 105-108.

[2] The SKOLKOVO Center for Educational Development has released a new study "The Greenfield Era in Education", Skolkovo: Moscow School of Management. October 10, 2013. Retrieved from http://www.skolkovo.ru/public/ru/research/newsresearch/ item / 3891-2013-10-10-15 /

[3] S.L. Timkin, The era of massive open online courses as a stage in the development of open education, Natural science education: information technologies in higher and secondary schools, Moscow: Moscow University Press Vol. 15 (2019) 54-74.

[4] T.V. Semenova, K. A. Vilkova, Types of integration of massive open online courses in the educational process of universities, University Management: Practice and Analysis 6(21) (2017) 114-126.

[5] Ya.M. Roshchina, S.Yu. Roshchin, V.N. Rudakov, Demand for Massive Open Online Courses (MOOC) Experience of Russian Education, Education 1 (2018) 174-199.

[6] J.Deng, Research on Higher Vocational Students' Acceptance and Use of MOOC in Web Software Development Course, Boletín Técnico Vol. 55, Iss. 7 (2017) 689-695.

[7] S.H. Foerster, Global: Relax-Higher Education Won't Be Killed by MOOCs, in: G. Mihut, P. G. Altbach, H. Wit (eds) Understanding Global Higher Education. Global Perspectives on Higher Education, Rotterdam: SensePublishers, 2017, pp. 151-153.

[8] B.Grainger, Massive Open Online Course (MOOC) Report 2013, VOCEDplus, NCVERs International Tertiary Education and Research Database. London: University of London, 2013. Retrieved from: $\quad$ http://www.londoninternational. ac.uk/sites/default/files/documents/mooc report-2 013.pdf

[9] How to sell education on the Internet: an interview of Elena Masolova (Eduson) with Daphne Koller 
(Coursera). Retrieved from: https://www.eduson.tv/blog/coursera

[10] Documentation on the competitive selection for the provision of grants in the form of subsidies from the federal budget. Retrieved from: https://m.minobrnauki.gov.ru/ru/documents/card/?i d $4=1184$

[11] T.V. Semenova, L.M. Rudakova, Barriers in the passage of massive open online courses, Monitoring public opinion: economic and social changes 3 (2015) 36-48.

[12] And Litvinenko, What the Future MOOC is preparing for us, Science in Siberia, September 20, 2018. Retrieved from: http://www.sbras.info/articles/education/chtomook-gryadushchii-nam-gotovit

[13] Online courses of TSU on the Coursera platform became available to students from all over the world. Retrieved from: https://proonline.tsu.ru/news/detail.php?ELEMENT ID=917 $\underline{3}$

[14] Novosibirsk State University launches massive open online courses (MOOCs) on the world's largest educational platform Coursera. Retrieved from: https://nsu.ru/cd5cacd528a379b5aeafdb190d2f8f7c

[15] What is a MOOC? Retrieved from: https://mooc.tsu.ru/ru/

[16] T. Parsons, The school class as a social system, in: Harvard Education Review, 1959, pp. 297-318.

[17] J.F. Lyotard, The State of Postmodernity, Trans. from fr., St. Petersburg: Aleteya, 1998, 160 p.

[18] I. Waard, S. Abajian, M.S. Gallagher, R. Hogue, N. Keskin, A. Koutropoulos, O.C. Rodriguez, Using Learning and MOOCs to understand chaos, emergence, and complexity in education, International Review of Research in Open and Distance Learning 12(7) (2011) 94-115.

[19] S.A. Zolotukhin, Advantages and disadvantages of massive open online courses, Discussion 4 (2015) 97-103.

[20] R. Meyer, What it's like to teach a MOOC (and what the eck's a MOOC?), TheAtlantic, 2012. Retrieved from: http://www.theatlantic.com/technology/ archive/2012/07/what-its-like-to-teach-a-moocand-what-the-hecks-a-mooc/260000/

[21] A. Wojciechowski, L. Palmer, B. Individual student characteristics: Can any be predictors of success in online classes? Online Journal of Distance Learning Administration, Vol. 8, Iss. 2, 2005.
[22] V.S. Makarov, Massive Open Online Courses: Evaluations of Effectiveness and Expert Recommendations, Educational Technologies, Iss. 2,2014 . 